Revista Perspectivas Online: Exatas \& Engenharias Anais do V Seminário P\&D PROVIC/PIBIC II Encontro de Iniciação Científica CNPq Vol. 10, n² 29, Suplemento, 2020

\title{
O que é Startup Lab?
}

\author{
Diego Moreira Souzal, José Matheus Viveiros ${ }^{2}$, Shayana Tavares de Souza ${ }^{2}$, Pedro Henrique \\ Dutra de Abreu Mancini de Azevedo ${ }^{3}$ \\ (1) Aluno de Iniciação Científica do PROVIC - Curso de Engenharia Civil; (2) Aluno(a) de Iniciação Científica do PROVIC - Curso de Engenharia \\ Mecânica; (3) Pesquisador Orientador - Curso de Engenharia de Produção - Institutos Superiores de Ensino do CENSA - ISECENSA, Rua Salvador \\ Correa, 139, Centro, Campos dos Goytacazes, RJ, Brasil.
}

Estudos têm demonstrado que as universidades empreendedoras parecem ser a evolução natural das universidades tradicionais de ensino e pesquisa. Com base nisso, as universidades precisam adicionar experiência em novos métodos e abordagens as habilidades dos alunos, especialmente em relação à criação de startups. Nesse sentido, foi proposta uma nova estrutura a ser implantada nas universidades brasileiras, na qual denominamos Startup Lab. Essa estrutura inclui uma abordagem de aprendizagem autoguiada para ensinar a disciplina de empreendedorismo, usando três métodos de desenvolvimento de startups: Desenvolvimento de Clientes, Startup Enxuta e Bootstrapping. Estes métodos foram utilizados como base do nosso modelo uma vez que abrangem três grandes competências empreendedoras que pretendemos desenvolver nos alunos, que são as competências comerciais, de desenvolvimento de produtos e de autofinanciamento. Analisamos as diferenças entre o Startup Lab e dois outros agentes empreendedores tradicionais baseados em universidades brasileiras: Empresas Juniores e Incubadoras. Nossos resultados demonstraram que o Startup Lab se diferencia desses dois outros agentes em termos de objetivo, processo de aprendizagem, público, método de financiamento, supervisão e relação professor-aluno. Portanto, pesquisas futuras sobre o assunto devem ser exploradas a fim de saber se esta estrutura proposta contribui para o desenvolvimento das habilidades empreendedoras dos alunos na criação e gestão de startups.

Palavras-chave: Empreendedor; Universidades; Startups.

Instituição de Fomento: ISECENSA. 